\title{
Hydrocephalus research funding from the National Institutes of Health: a 10-year perspective
}

\author{
Clinical article
}

\author{
Paul Gross, B.A., ${ }^{1}$ Gavin T. Reed, M.P.H., ${ }^{1}$ Rachel Engelmann, M.P.H., ${ }^{1}$ \\ AND JoHN R. W. KeSTLE, M.D. ${ }^{2}$ \\ ${ }^{1}$ Hydrocephalus Association, Bethesda, Maryland; and ${ }^{2}$ Department of Surgery, University of British \\ Columbia, Vancouver, British Columbia, Canada
}

\begin{abstract}
Object. Funding of hydrocephalus research is important to the advancement of the field. The goal of this paper is to describe the funding of hydrocephalus research from the National Institutes of Health (NIH) over a recent 10year period.

Methods. The NIH online database RePORT (Research Portfolio Online Reporting Tools) was searched using the key word "hydrocephalus." Studies were sorted by relevance to hydrocephalus. The authors analyzed funding by institute, grant type, and scientific approach over time.

Results. Over \$54 million was awarded to 59 grantees for 66 unique hydrocephalus proposals from 48 institutions from 2002 to 2011. The largest sources of funding were the National Institute of Neurological Disease and Stroke and the National Institute of Child Health and Human Development. Of the total, \$22 million went to clinical trials, $\$ 15$ million to basic science, and \$10 million to joint ventures with small business (Small Business Innovation Research or Small Business Technology Transfer). Annual funding varied from $\$ 2.3$ to $\$ 8.1$ million and steadily increased in the second half of the observation period. The number of new grants also went from 15 in the first 5 years to 27 in the second 5 years. A large portion of the funding has been for clinical trials. Funding for shunt-device development grew substantially. Support for training of hydrocephalus investigators has been low.

Conclusions. Hydrocephalus research funding is low compared with that for other conditions of similar health care burden. In addition to NIH applications, researchers should pursue other funding sources. Small business collaborations appear to present an opportunity for appropriate projects. (http://thejns.org/doi/abs/10.3171/2013.11.PEDS13197)
\end{abstract}

KeY Words • hydrocephalus • funding • National Institutes of Health • research

$\mathrm{H}$ YDROCEPHALUS affects at least 1 in 1000 live newborns, and the cost of hydrocephalus in terms of both health care dollars and quality of life is significant. ${ }^{2}$ In 2003 there were 39,900 admissions, 433,000 hospital days and $\$ 2$ billion in charges for pediatric hydrocephalus. Clinical research into the condition is largely the domain of neurosurgeons, who rarely have sufficient protected time to conduct meaningful work. Basic science investigators in hydrocephalus are a rare breed with limited resources and a small peer group that has not grown

\footnotetext{
Abbreviations used in this paper: MOMS = Management of Myelomeningocele Study; NIBIB = National Institute of Biomedical Imaging and Bioengineering; NICHD = National Institute of Child Health and Human Development; NIH = National Institutes of Health; NINDS = National Institute of Neurological Disease and Stroke; RePORT = Research Portfolio Online Reporting Tools; SBIR $=$ Small Business Innovation Research; STTR = Small Business Technology Transfer.
}

over the years. Advances in the field will depend on an influx of bright young minds with new ideas and techniques and the ability to compete for limited public funding.

The amount and distribution of public funding for hydrocephalus research is not well described. The goal of this study was to analyze the public funding of hydrocephalus research over the past 10 years (2002-2011). This work should help the hydrocephalus research community understand what types of research are being funded, where, and by whom and therefore bring light to opportunities going forward.

\section{Methods}

To capture public funding over the last 10 years, we used the National Institutes of Health (NIH) online database, Research Portfolio Online Reporting Tools (RePORT; www.report.nih.gov). This database stores pertinent information about studies the NIH has funded, 
including the type of award and the amount funded by year. RePORT is searchable using key words. The key term "hydrocephalus" was used in our query, and the returned studies were examined and sorted based on their relevance to hydrocephalus. Studies that were questionably related to hydrocephalus were reviewed by the members of the medical advisory board of the Hydrocephalus Association, which includes clinical and basic scientists. The studies deemed relevant to hydrocephalus (pediatric and/or adult) were those with significant implications for the condition in terms of advancing the knowledge base or improving some element of clinical decision making, treatment, or outcomes. Any gaps in funding or difficulties in understanding the nature of a grant's funding were addressed with the NIH staff. The relevant studies were then categorized by scientific approach. From these categorizations and the variables provided for each study by the RePORT tool, an in-depth analysis was done to create a picture of the trends of funding in hydrocephalus research from 2002 through 2011.

\section{Results}

The total amount of NIH spending on hydrocephalusrelated research from 2002 through 2011 was \$51,553,143. Hydrocephalus researchers were also the beneficiaries of an additional \$2,503,534 in funding from the American Rehabilitation and Recovery Act. While NIH disregards American Rehabilitation and Recovery Act funding in the analysis of its own portfolio, it was included in this paper to allow us to completely represent the research that has been funded by public dollars. Thus, the denominator for calculating percentages was $\$ 54,056,677$.

The National Institute of Neurological Disease and Stroke (NINDS) and the National Institute of Child Health and Human Development (NICHD) were the 2 NIH institutes responsible for the majority of the funding, contributing $85 \%$ of the total (Fig. 1). The NICHD funded $\$ 24,421,695(45 \%)$ of hydrocephalus-related research, while the NINDS funded \$21,853,949 (40\%). Among the other NIH agencies that contributed dollars to such projects were the National Institute of Biomedical Imaging and Bioengineering (NIBIB), National Institute of Aging (NIA), National Institute of Mental Health (NIMH), National Heart, Lung, and Blood Institute (NHLBI), National Institute of Allergy and Infectious Disease (NIAID), National Institute of Environmental Health Sciences (NIEHS), and the Office of the Director.

The NIH used these funds to award 59 grantees and 66 unique proposals from 48 institutions. Of the funding contributed to these awards, $\$ 22,045,944$ was spent on clinical trials, $\$ 15,744,180$ was spent on basic science research projects, and $\$ 10,055,385$ was contributed to Small Business Innovation Research (SBIR) or Small Business Technology Transfer Program (STTR) ventures. The remaining $12 \%$ of funds were invested, in descending order, in intramural research, research centers, and individual training awards (Fig. 2).

The grants awarded were categorized by scientific approach to highlight the methodologies within hydrocepha-

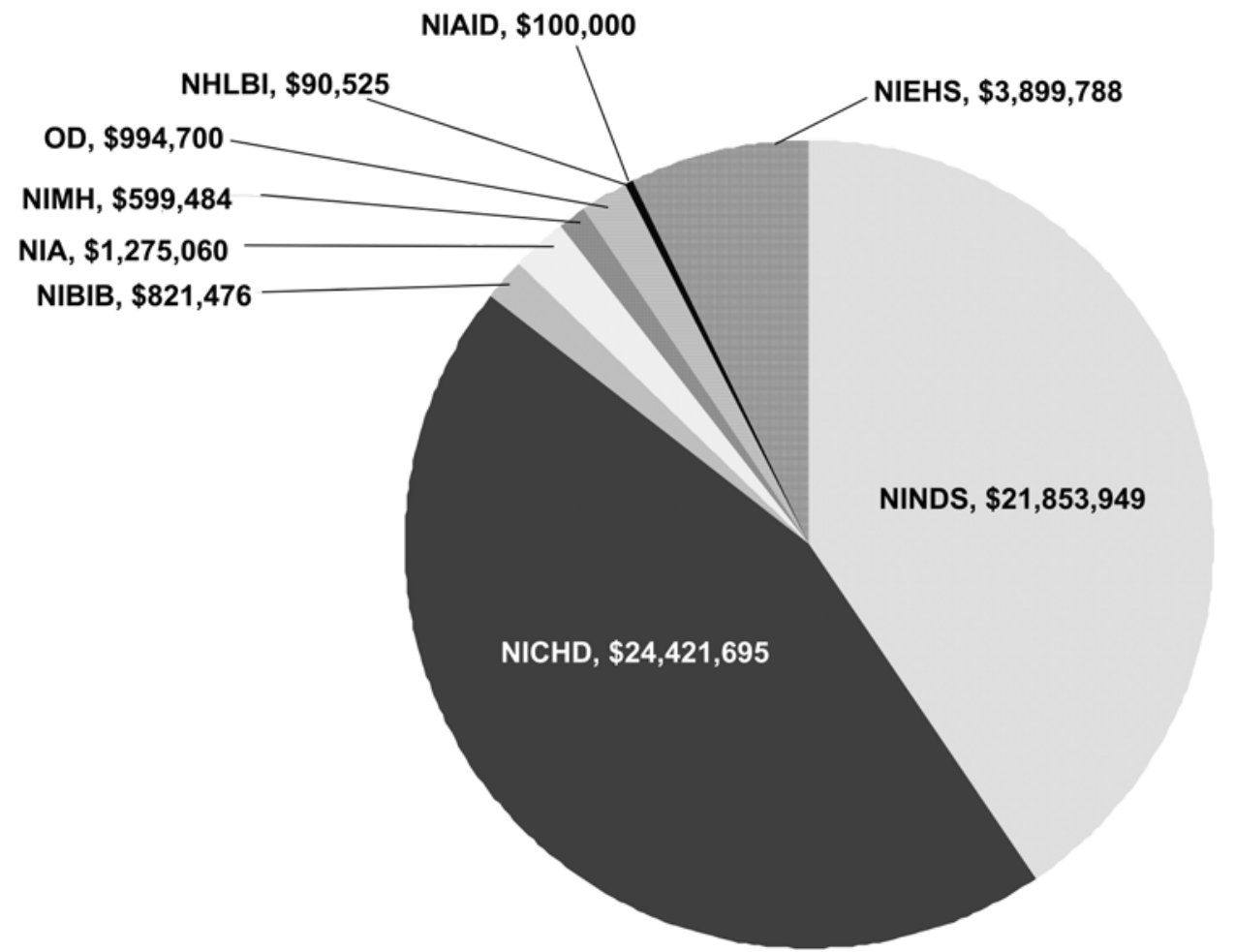

FIG. 1. Breakdown of spending from the NIH for hydrocephalus research by institute. The National Center for Research Resources and the National Institute of Diabetes and Digestive and Kidney Diseases provided no funding. NIA = National Institute of Aging; NIAID = National Institute of Allergy and Infectious Disease; NIEHS = National Institute of Environmental Health Sciences; $\mathrm{NIMH}=$ National Institute of Mental Health; NHLBI = National Heart, Lung, and Blood Institute; OD = Office of the Director. 
Hydrocephalus research funding from NIH

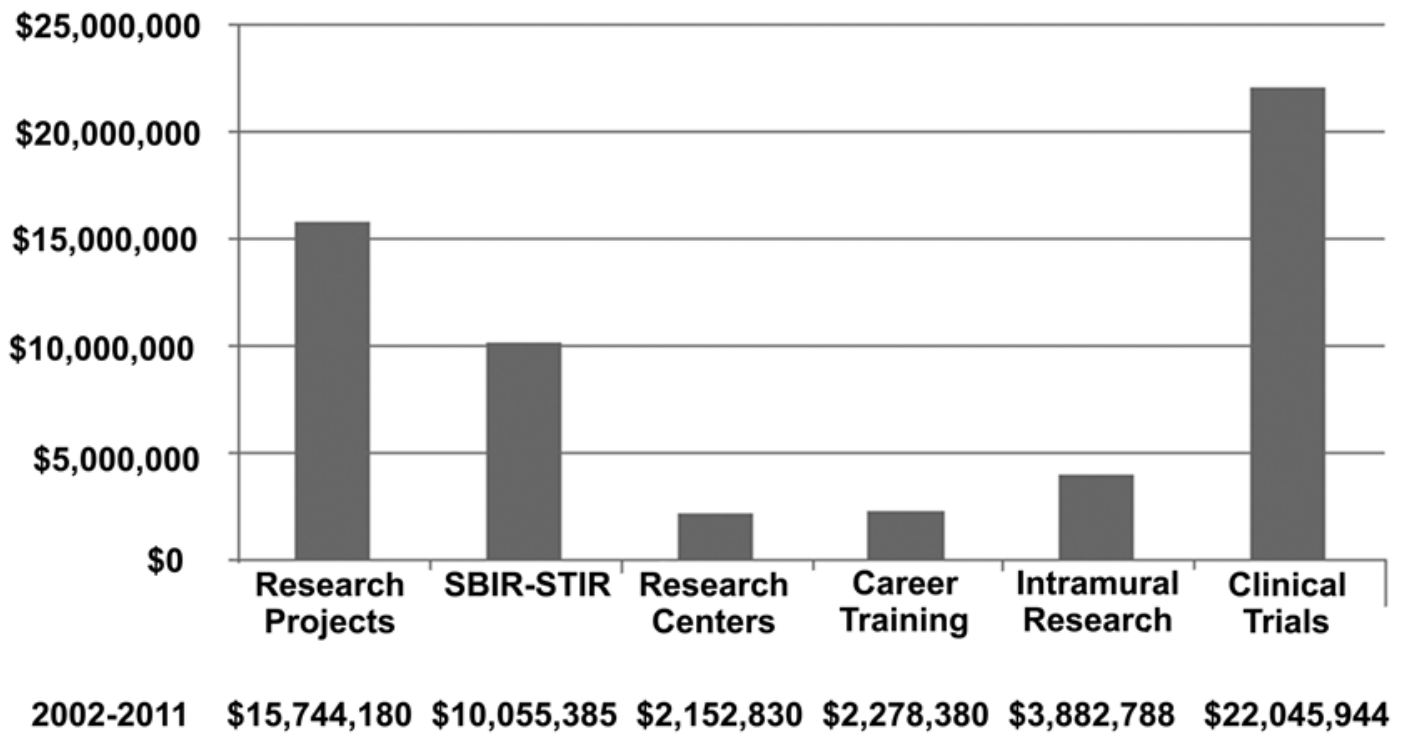

Fig. 2. Breakdown of NIH spending for hydrocephalus research by grant type.

lus research that are getting the most attention from public funders (Fig. 3). The largest amount of funds, \$25,117,186 (46\%), was allotted to clinical, patient-based studies. The majority of these clinical study funds $-\$ 22,045,944$ or $88 \%$ - went to a multicenter randomized trial assessing fetal surgery for myelomeningocele (Management of Myelomeningocele Study [MOMS]). ${ }^{1}$ After clinical studies, the next largest amount, $\$ 9,610,634(18 \%)$, went to shuntdevice development projects $(90 \%$ to small businesses and $10 \%$ to university researchers). Basic science projects related to hydrocephalus received $\$ 9,088,014(17 \%)$. The remaining $9 \%, 5 \%$, and $4 \%$ went to CSF dynamics, other device development, and cognitive-behavioral research, respectively.

The total annual funding (Fig. 4) varied over the last 10 years, from a low of $\$ 2,305,023$ in 2005 to a high of $\$ 8,195,553$ in 2010 . There was a steady increase in annual funding after the $2005 \mathrm{NIH}$-sponsored consensus conference on hydrocephalus. ${ }^{3}$ The annual funding was significantly impacted by the MOMS trial, which began in 2002

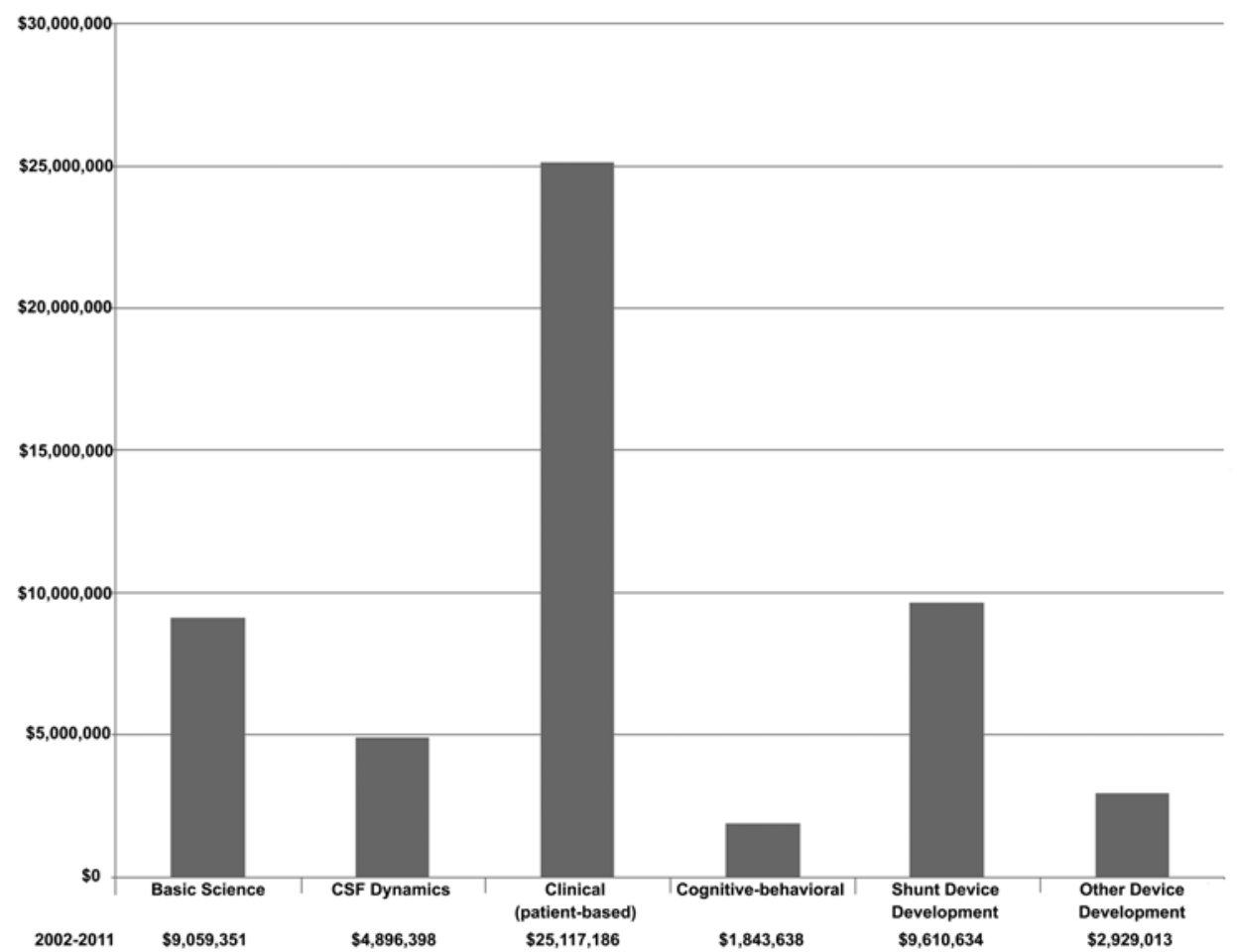

FIG. 3. Breakdown of NIH spending on hydrocephalus research by scientific approach. 


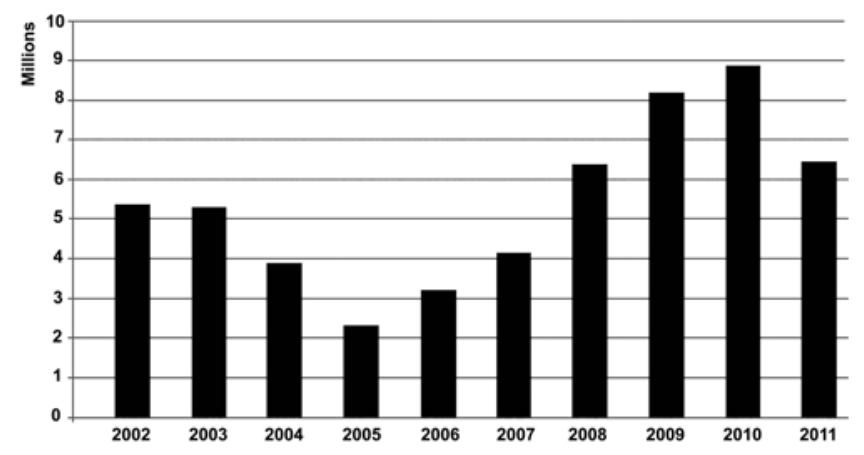

FIG. 4. Total NIH spending (in millions) on hydrocephalus research from 2002 through 2011.

and received an average of $\$ 2.2$ million per year during the period of observation. Over the past 10 years, the relative contribution from different institutes has varied (Fig. 5). Funding from NICHD steadily decreased, from more than $\$ 4$ million per year in 2002 and 2003 to just $\$ 350,000$ in 2011. This occurred because the NICHD funding was largely concentrated on the MOMS trial, which is winding down. In contrast, the NINDS funding of hydrocephalus research has been steadily increasing over the past 10 years. Funding levels in 2002 were around only \$1 million and had risen to over \$5 million in 2011.

To evaluate the funding of new hydrocephalus research activity, we analyzed the new grants funded from 2002 through 2011 (Fig. 6). In the first 5 years (20022006), there were 15 new grants funded. From 2007 through 2011, 27 new grants were funded. The type of research funded has changed over the past decade as well. As has been previously discussed, clinical and shunt-device development research has received the majority of funding over this time, and it is in these 2 areas that we see the largest changes (Fig. 7). Clinical research funding has fluctuated immensely throughout the time period studied, starting at around $\$ 4$ million per year at the beginning of the decade, dipping below $\$ 1$ million in 2005 , increasing back to nearly $\$ 4$ million in 2008 , and decreasing to roughly $\$ 171,000$ in 2011 . Shunt-device development

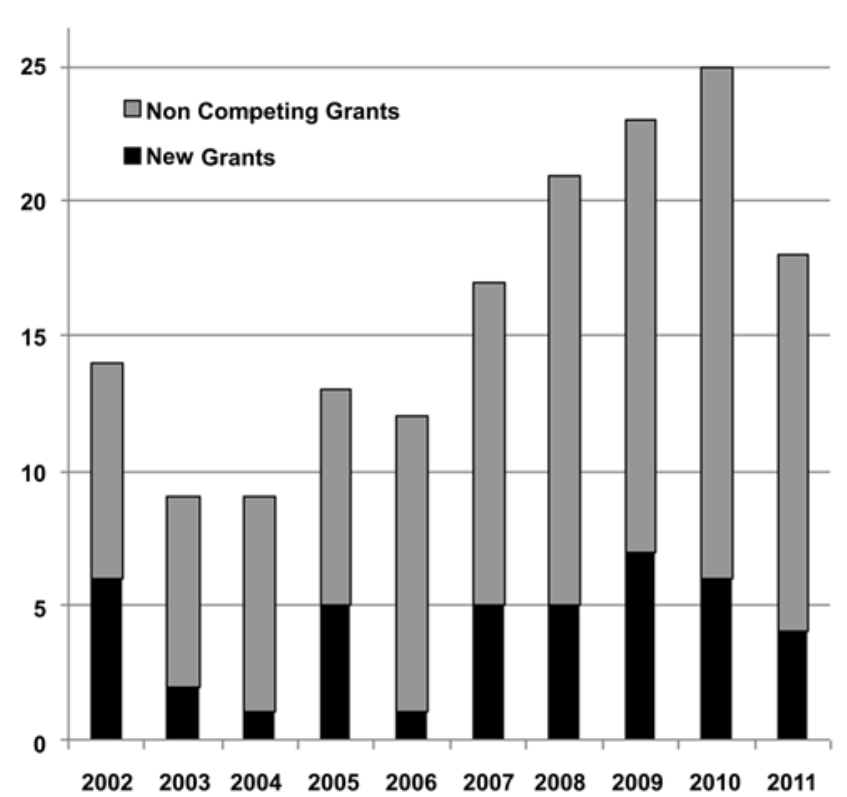

FIG. 6. Number of grants awarded by the NIH for hydrocephalus research from 2002 through 2011.

funding has shown dramatic increases in recent years, rising from $\$ 404,244$ in 2007 to $\$ 4,507,683$ in 2011 . Since 2005, basic science research has also increased on the whole, rising from $\$ 44,846$ to a high of $\$ 2,640,766$ in 2009. Funding in the area of CSF dynamics also saw improvements as of late, as there were no projects funded in the area in 2008 , and since that time over $\$ 500,000$ has been allotted to it per year. The other 2 types of research categorized, cognitive-behavioral and other device development, fluctuated between no projects funded and 1 being funded, but both areas attract small amounts of NIH support.

Funding to support research using engineering and mathematical modeling techniques increased exponentially toward the end of the decade. This appeared to be in part due to its relevance in shunt-device development.

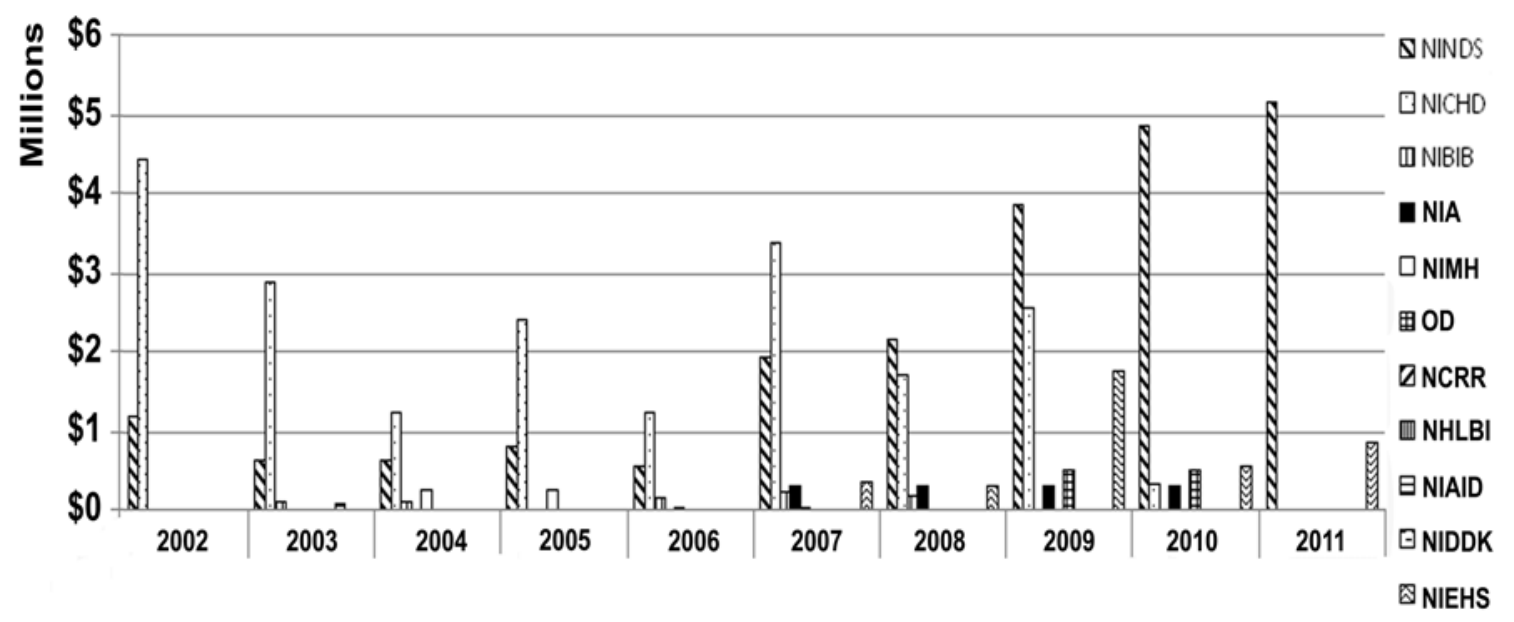

FIG. 5. NIH spending on hydrocephalus research by the top 5 institutes from 2002 through 2011. NIA = National Institute of Aging. 


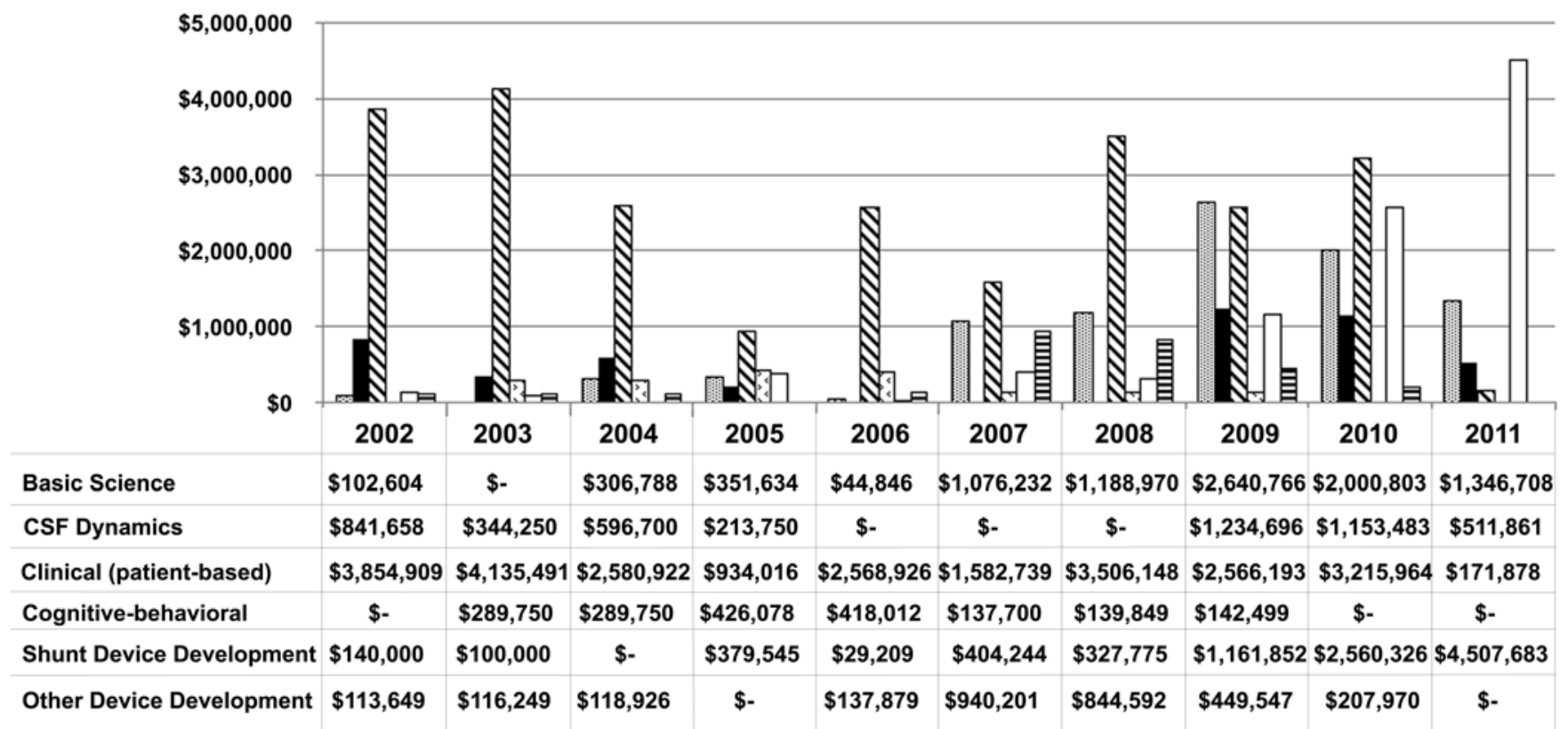

FIG. 7. NIH spending on hydrocephalus research by scientific approach from 2002 through 2011.

Proteomics and genomics research increased from nearly no dollars invested in the early part of the decade to a spike of $\$ 3,565,013$ in 2009. The final trend of note would be the increase in the use of animal model research funding, which rose from $\$ 182,725$ in 2005 to over $\$ 2$ million in 2011.

Support for the training of hydrocephalus investigators has been low. Over the period studied, there were only 4 career $(\mathrm{K})$ and 4 training $(\mathrm{F})$ awards granted, totaling $\$ 2,278,380$ (Fig. 2).

\section{Discussion}

National Institutes of Health funding of hydrocephalus research seems low compared with that of diseases of similar health care burden. Over the last 3 years, public funding of research on Parkinson disease, cystic fibrosis, and epilepsy was \$629 million, \$341 million, and \$559 million, respectively. Public funding of hydrocephalus research over that same period amounted to about \$23 million, meaning that the other disease research efforts were funded 15 to 27 times more than hydrocephalus efforts. Why is this? Are there enough applications for hydrocephalus-related grants? The RePORT system does not keep a record of the number of applications received. Assuming that hydrocephalus applications are on par with other grant requests in terms of quality, the NINDS payline would suggest that there are between 27 and 40 applications submitted each year. This is a small number, and it is likely that more applications will result in more funded grants. It therefore seems important to attract scientists to the field and to support them to train in hydrocephalus research. There was 1 hydrocephalus-specific Program Announcement regarding enhancements to CSF shunts in 2009. A large number of applications were received, demonstrating the power of NIH to draw researchers to a problem once it is deemed a priority for an institute. More of such initiatives to attract researchers are important to the future of the field.

There has been a shift in funding focus toward devices mainly through SBIR/STTR grants. During 2010 and $2011,70 \%$ of the grants funded were for SBIRs. The $\mathrm{NIH}$ is legislated to set aside $2.6 \%$ of its funds for smallbusiness grants. This requirement has allowed a higher payline in these categories, which is above $25 \%$ in many cases. Collaborations between university-based researchers and small business therefore represent a significant opportunity for hydrocephalus research.

Because the publicly funded hydrocephalus research portfolio is small, it can be significantly altered by a single large grant. This appears to be the case during our observation period. The high cost of MOMS relative to the overall hydrocephalus portfolio certainly had an impact on the funding picture and on our analysis. The contribution of the NICHD may be deceiving because it was nearly all awarded to the MOMS trial. Not only does this study encompass nearly all of the funding from NICHD, but its funding comprises nearly $50 \%$ of all of the public funding for hydrocephalus-related research during this time period.

Finally, the limited resources available at the NIH highlight the importance of other sources of hydrocephalus funding. The Hydrocephalus Association has made significant changes in the last 5 years and now funds clinical and basic research in hydrocephalus. They offer Mentored Young Investigator awards to increase the pool of trained hydrocephalus researchers. Other private foundations have also been funding hydrocephalus research. These sources are essential and play a key role in helping investigators generate pilot data to support larger NIH applications. 


\section{P. Gross et al.}

\section{Conclusions}

Based on our research, we found the following: 1) hydrocephalus research funding is low, at least partially because of a small number of researchers and applications, 2) partnership with small business, when appropriate, represents an opportunity for hydrocephalus research, and 3) in addition to the NIH, other sources of funding should be pursued by hydrocephalus researchers.

\section{Disclosure}

The authors report no conflict of interest concerning the materials or methods used in this study or the findings specified in this paper.

Author contributions to the study and manuscript preparation include the following. Conception and design: all authors. Acquisition of data: all authors . Analysis and interpretation of data: all authors. Drafting the article: Kestle, Gross. Critically revising the article: all authors. Reviewed submitted version of manuscript: all authors. Approved the final version of the manuscript on behalf of all authors: Kestle.

\section{References}

1. Adzick NS, Thom EA, Spong CY, Brock JW III, Burrows PK, Johnson MP, et al: A randomized trial of prenatal versus postnatal repair of myelomeningocele. N Engl J Med 364:9931004, 2011

2. Simon TD, Riva-Cambrin J, Srivastava R, Bratton SL, Dean JM, Kestle JR: Hospital care for children with hydrocephalus in the United States: utilization, charges, comorbidities, and deaths. J Neurosurg Pediatr 1:131-137, 2008

3. Williams M, McAllister J, Walker M, Kranz D, Bergsneider M, Del Bigio M, et al: Priorities for hydrocephalus research: report from an NIH-sponsored workshop. J Neurosurg 107 (5 Suppl):345-357, 2007

Manuscript submitted April 15, 2013.

Accepted November 7, 2013.

Please include this information when citing this paper: published online December 6, 2013; DOI: 10.3171/2013.11.PEDS13197.

Address correspondence to: John R. W. Kestle, M.D., Department of Surgery, University of British Columbia, Rm. 3100, 910 W. 10th Ave., Vancouver, BC V5Z 4E3, Canada. email: john.kestle@ubc.ca. 